\title{
Practical considerations and patient selection for intrathecal drug delivery in the management of chronic pain
}

This article was published in the following Dove Press journal:

Journal of Pain Research

10 November 2014

Number of times this article has been viewed

\section{Michael Saulino ${ }^{1,2}$ \\ Philip S Kim ${ }^{3,4}$ \\ Erik Shaw ${ }^{5}$}

'MossRehab, Elkins Park, PA, USA; ${ }^{2}$ Department of Rehabilitation

Medicine, Jefferson Medical College, Philadelphia, PA, USA; ${ }^{3}$ Helen F

Graham Cancer Center, Christiana

Care Health System, Newark, DE,

USA $;{ }^{4}$ Center for Interventional Pain

Spine, LLC., Bryn Mawr, PA,

USA; ${ }^{5}$ Shepherd Pain Institute,

Shepherd Center, Atlanta, GA, USA
Correspondence: Michael Saulino

MossRehab, 60 East Township

Line Road, Elkins Park, PA 19027, USA

Tel + I 2I5 6636607

Fax + I 2156636653

Email docsaulino@msn.com
Abstract: Chronic pain continues to pose substantial and growing challenges for patients, caregivers, health care professionals, and health care systems. By the time a patient with severe refractory pain sees a pain specialist for evaluation and management, that patient has likely tried and failed several nonpharmacologic and pharmacologic approaches to pain treatment. Although relegated to one of the interventions of "last resort", intrathecal drug delivery can be useful for improving pain control, optimizing patient functionality, and minimizing the use of systemic pain medications in appropriately selected patients. Due to its clinical and logistical requirements, however, intrathecal drug delivery may fit poorly into the classic pain clinic/interventional model and may be perceived as a "critical mass" intervention that is feasible only for large practices that have specialized staff and appropriate office resources. Potentially, intrathecal drug delivery may be more readily adopted into larger practices that can commit the necessary staff and resources to support patients' needs through the trialing, initiation, monitoring, maintenance, and troubleshooting phases of this therapy. Currently, two agents - morphine and ziconotide - are approved by the United States Food and Drug Administration for long-term intrathecal delivery. The efficacy and safety profiles of morphine have been assessed in long-term, open-label, and retrospective studies of $>400$ patients with chronic cancer and noncancer pain types. The efficacy and safety profiles of ziconotide have been assessed in three double-blind, placebo-controlled trials of 457 patients, and safety has been assessed in 1,254 patients overall, with severe chronic cancer, noncancer, and acquired immunodeficiency syndrome pain types. Both agents are highlighted as first-line intrathecal therapy for the management of neuropathic or nociceptive pain. The purpose of this review is to discuss practical considerations for intrathecal drug delivery, delineate criteria for the identification and selection of candidates for intrathecal drug delivery, and consider which agent may be more appropriate for individual patients.

Keywords: review, patient selection, chronic pain, intrathecal, drug delivery

\section{Introduction}

Although the full impact of chronic pain is probably not well documented, abundant evidence indicates that chronic pain presents patients, clinicians, and health care systems with continuing and increasing challenges. ${ }^{1,2}$ Chronic pain, which may be defined as pain that persists beyond "several months" ("3 to 6 months, but certainly longer than "normal healing",) or "pain of a duration or intensity that adversely affects the function or well-being of the patient"3 already afflicts an estimated 100 million individuals in the United States at an annual cost of $\$ 560$ billion- $\$ 635$ billion for treatment and lost productivity. ${ }^{1}$ In the near future, costs associated with chronic pain will likely become an even greater burden, due to the increasing prevalence of chronic pain within the growing older population, its adverse impact on quality of life and health status, the 
increased recognition and treatment of chronic pain, and the introduction of newer treatment technologies that may extend lives at the cost of people having to live with chronic pain. ${ }^{1}$

The cumulative negative impact of chronic pain on a patient's physical, mental, and emotional health can contribute to a downward spiral of impaired socialization and functioning that may lead to anger, frustration, and mood and anxiety disorders. ${ }^{1,4-6}$ Health care professionals should bear in mind that some patients with chronic pain may become skeptical of pain management in general and dissatisfied with - and even angry about - their treatment and treating physician. ${ }^{1,7,8}$ The adverse impact of chronic pain on patients' lives may cause them to experience frustration following repeated failure to achieve total pain relief, despite trials of several traditional approaches; these patients may begin to "doctor shop" and/or use unproven alternative therapies. ${ }^{1}$ Therefore, the pain specialist needs to consider all appropriate management approaches when working with individual patients who are experiencing chronic pain. ${ }^{9,10}$

Multiple barriers to the effective recognition and management of chronic pain persist (Table 1). ${ }^{1,11-14}$ For example, definitive diagnosis and adequate management continue to be elusive targets for many patients with chronic pain. ${ }^{1}$ Additionally, the subjective nature of pain and the lack

Table I Barriers to the recognition and management of chronic pain

- Absence of definitive evidence regarding therapies, whether singleagent or combination/multimodality regimens, that can "cure" chronic pain in specific patient populations ${ }^{11-14}$

- Lack of well-validated, evidence-based management guidelines in many chronic pain states'

- Failure to follow available guidelines in some chronic pain states'

- Limited understanding of pain pathophysiology'

- Lack of a single, universally accepted measure of pain'

- Few comparative effectiveness trials involving current treatment options'

- Limited awareness among some health care professionals regarding recent advances in understanding pain states and best practices in prevention and treatment ${ }^{\prime}$

- Difficulties for primary care physicians to integrate within models of care for referring patients to appropriate specialists'

- Limited understanding of the importance of pain management among patients, health care providers, employers, and insurers'

- Regulatory and legal constraints on the appropriate use of certain treatment modalities, such as opioids'

- Constraints imposed by third-party payers, including workers' compensation plans'

- Limited access to new treatment options due to scientific, clinical, regulatory, and market forces' of correlation that sometimes exists between a patient's perception of chronic pain and the extent of documentable tissue pathology contribute to the diagnostic challenge. ${ }^{8}$ Accordingly, a multidisciplinary approach to pain management may be needed for many of these patients. ${ }^{1,8}$ This team approach generally involves a pain specialist (typically an anesthesiologist, physical and rehabilitation medicine or occupational medicine physician, psychiatrist, or neurologist, with subspecialty training), psychologist, physical therapist, and occupational therapist, as well as nursing and pharmacy specialists. The activities of these teams are often coordinated through pain centers that provide a range of pain management techniques. ${ }^{1}$

With regard to intrathecal (IT) therapy in particular, the recently reported failure of IT gabapentin to provide effective relief of chronic noncancer pain highlights the importance of another area of pain management: proper therapy selection for individual patients. ${ }^{15}$ The observed failure in this instance may have resulted, in part, from the intentionally broad patient selection criteria and, consequently, heterogeneous study population - a population in which oral delivery of this molecule may not have been expected to exert a beneficial effect. ${ }^{15}$

Given the ongoing need to consider all appropriate options to provide greater relief for patients with chronic pain, and to optimize their ability to perform activities of daily living, this review identifies practical considerations and patient selection criteria that can help guide the use of IT drug delivery and selection of an appropriate IT therapy agent.

\section{Current perceptions of IT therapy and practice}

By the time patients with severe chronic pain present to pain specialists for evaluation, they may have already tried a variety of self-management techniques, been seen by several other physicians, received various diagnoses, and tried and failed an array of nonpharmacologic and pharmacologic interventions. ${ }^{1}$ Therefore, pain specialists' management of chronic pain may include an array of interventions tailored to individual patient needs (Table 2). ${ }^{1,8,11-14,16-27}$ Some of these options, especially the surgical interventions, are reserved for use after failure of other options. ${ }^{1,11,12,14}$

Pain specialists typically reserve IT therapy for use late in the treatment pathway, after the failure of more conservative/less invasive approaches. ${ }^{14}$ IT drug delivery may be perceived as an intervention of "last resort" because it fits poorly into the classic pain clinic/interventional model due to the need for greater commitment by the patient, the 
Table 2 Potentially useful interventions in the management of patients with severe chronic pain

\begin{tabular}{|c|c|}
\hline Type of intervention & Examples \\
\hline $\begin{array}{l}\text { Noninvasive, nonpharmacologic } \\
\text { interventions }{ }^{1,8,14,16-24}\end{array}$ & $\begin{array}{l}\text { - Rehabilitative/physical therapy } \\
\text { - Exercise strategies } \\
\text { - Psychological counseling } \\
\text { - Biofeedback } \\
\text { - Group counseling } \\
\text { - Complementary and alternative medicine }\end{array}$ \\
\hline $\begin{array}{l}\text { Medications self-administered by } \\
\text { patients }{ }^{1,8,14,24-26}\end{array}$ & $\begin{array}{l}\text { - Nonsteroidal anti-inflammatory drugs (for example, aspirin, ibuprofen, indomethacin, diclofenac) } \\
\text { - Antipyretic analgesics (for example, acetaminophen) } \\
\text { - Opioids } \\
\text { - Tramadol } \\
\text { - Antidepressants with both norepinephrine and serotonin reuptake inhibition } \\
\text { - Serotonergic drugs } \\
\text { - Anticonvulsants (gabapentin, pregabalin) } \\
\text { - Complementary and alternative medicine }\end{array}$ \\
\hline Stimulation techniques ${ }^{8}$ & $\begin{array}{l}\text { - Transcutaneous electrical nerve stimulation } \\
\text { - Spinal cord (or dorsal column) stimulation } \\
\text { - Acupuncture } \\
\text { - Other forms of neuromodulation }\end{array}$ \\
\hline Regional anesthetic interventions ${ }^{1,8,11,13,27}$ & $\begin{array}{l}\text { - Sacroiliac joint injections } \\
\text { - Epidural steroid injections } \\
\text { - Cervical/thoracic/lumbar facet-joint nerve blocks } \\
\text { - Trigger-point injections } \\
\text { - Intraspinal/intrathecal drug delivery }\end{array}$ \\
\hline Surgery $1,11,12,14$ & $\begin{array}{l}\text { - Implantation of devices (for example, spinal cord stimulation systems or spinal analgesic infusion } \\
\text { - Pumps) } \\
\text { - Drocedures for spinal decompression (for example, laminectomies, discectomies) } \\
\text { - Spinal fusion } \\
\text { - Nerve decompression (for example, carpal tunnel syndrome, trigeminal neuralgia) } \\
\text { - Ablative procedures (for example, nerve section [neurotomy, rhizotomy], cordotomy), which } \\
\text { are typically reserved for patients who fail other treatments }\end{array}$ \\
\hline
\end{tabular}

pain specialist, and the pain practice. Nevertheless, for the past two decades, IT therapy has increasingly been used in the management of chronic moderate to severe pain in cancer patients and noncancer patients. ${ }^{28-30}$ Although more physicians have been prescribing IT therapy, this mode of treatment has initial and continuing challenges that include trialing, implantation, monitoring for analgesic response and adverse effects, and maintenance and drug refills. ${ }^{14,28,31}$ Additional barriers to IT therapy include adverse effects related to specific drugs and pharmacologic tolerance to opioids, ${ }^{32,33}$ pump and catheter complications, management of coexisting disease (for example, depression and anxiety), and financial considerations. ${ }^{1,14,28,34,35}$

These challenges may cause many pain specialists to perceive IT drug delivery as a "critical mass" intervention that fits more readily into larger pain practices that have specialized staff and resources. Efforts to better inform physicians in a variety of settings regarding the appropriate use of IT therapy may help to deliver more effective analgesia with this mode of treatment to more patients in need, with the potential of minimizing the use of systemic analgesics. ${ }^{28}$

\section{Key challenges for the management of refractory chronic pain}

Patients who are candidates for IT therapy (those with severe chronic pain that is refractory to other treatments) pose several challenges that require a comprehensive approach by the pain specialist. From a clinical perspective, the pain specialist needs to understand each patient's full medical, social, pain, and medication history, as well as the diagnostic workup available to date. ${ }^{36}$ Helping patients understand that chronic pain can have a substantial negative impact on their lives and daily functioning, and setting appropriate expectations for treatment, are important priorities..$^{1,4,5}$ Accordingly, the pain specialist needs to evaluate the patient's current psychological state in the context of chronic pain, with respect to feelings of helplessness/lack of control, depression, and suicidal ideation/attempts, as well as the patient's 
decision-making capacity. Evidence of psychiatric, mood, or anxiety disorders, or "pain catastrophizing", should be assessed and addressed through an integrated biopsychosocial treatment plan. ${ }^{1,37}$

Obtaining an accurate, comprehensive review of the patient's pain medication history can present its own challenges. The goal is to record the specific agents that the patient has previously tried, along with the dosage, duration, and reason for discontinuing therapy. For patients living with chronic pain, this list and its details can be long and complicated. Nonetheless, the pain specialist relies on this valuable information as a clinical baseline and also as a means to learn about the patient's perceptions of "treatment failure" and its causes.

Working with the patient to set realistic expectations and to reach an agreement on appropriate definitions of "treatment success" constitutes a crucial management step for pain specialists. The patient's ultimate satisfaction with treatment depends on it meeting or exceeding his or her personal expectations, whether defined in terms of reducing pain intensity, as measured via a declining pain score on a visual analog scale, or in restoring functionality to a specific, previously impaired activity of daily living. ${ }^{38}$ Finally, obtaining details of each patient's current use of nonanalgesic medications for comorbid conditions other than pain provides the pain specialist with a complete clinical perspective that can help him or her avoid drug interaction problems when formulating a treatment plan. ${ }^{36}$

\section{Practical considerations for IT drug delivery}

Clinicians who select IT therapy as a treatment for patients with severe chronic pain must decide whether to refer these patients to a specialty practitioner or to retain and treat them. Referral is the appropriate choice for practices that cannot fully accommodate all aspects of IT drug delivery, from evaluation, trialing, implantation, and long-term management to troubleshooting. Retaining such patients for treatment necessitates a commitment to the requirements of IT therapy, starting with a comprehensive assessment of all new patients and a reassessment of current patients with unresolved pain to rule out misdiagnoses or correctable structural issues. ${ }^{36}$

The decision to treat a patient with IT drug delivery involves recognition of the goals of IT trialing and/or therapy, which include the relief of pain, as evaluated on the basis of pain score reductions and/or improvements of highest priority to the individual patient (for example, specific functionality, mood, quality of life) and reduction in systemic opioid use. ${ }^{38}$ From trialing onward, treatment with IT drug delivery requires a commitment to continual monitoring and follow-up 24 hours a day, with appropriate allocation of practice resources to provide these services. ${ }^{28,31}$ Physicians who incorporate IT drug delivery into their practices should anticipate calls from other health care professionals, especially emergency department physicians to whom patients on IT drug delivery may present.

Pain specialists who offer IT drug delivery should identify appropriate therapeutic goals and patient comorbidities of concern, taking steps to optimally manage blood glucose control, sleep apnea, and infection/colonization-related issues prior to trialing. ${ }^{28,31}$ Additionally, pain specialists should consider procedural issues and potential infection risks (for example, the possibility of methicillin-resistant Staphylococcus aureus [MRSA] in community-dwelling patients and appropriate presurgical prophylaxis). ${ }^{28}$ The relevance of MRSA risk with regard to outpatient procedures continues to grow, especially since the incidence of community-acquired infection surpassed that of hospitalonset infection in the most recent surveillance data from the Centers for Disease Control and Prevention. ${ }^{39,40}$

Weaning of systemic opioids prior to IT trialing may be considered, although it is not essential since a reduction in opioid consumption can be a useful metric of success with IT drug delivery. ${ }^{31,41}$ Prescribers need to work with patients and caregivers to identify and be prepared to respond to potential adverse effects of IT drug delivery, such as granuloma formation at the catheter tip when opioids are being used. ${ }^{28,31,42,43}$ Finally, due to the nature of IT drug delivery, treating physicians need to consider the patient's insurance coverage, and they may need to work closely with drug/device manufacturers and payers regarding financing of the patient's IT drug delivery program. ${ }^{28}$

Although further work is needed to demonstrate the economic benefits of IT drug delivery, available data generally support the conclusion that IT drug delivery is associated with higher initial costs, but lower maintenance costs, when compared with conventional medical therapy for chronic pain. For example, a decision-tree model based on a cohort of 1,000 patients with chronic pain due to failed back surgery syndrome showed that, in all instances but the worst-case scenarios, IT morphine would be a cost-effective alternative to medical management through 5 years of care. ${ }^{44}$ Another study showed that IT drug delivery provided a cost-effective alternative to conventional pain therapy for the long-term (5-year) management of chronic pain (for example, low back pain due to failed back syndrome). ${ }^{45}$ 
These reports have been supported, and their results extended, in more recent cost-effectiveness analyses of IT drug delivery versus the conventional medical management of chronic noncancer and cancer pain with medications, including opioids and ziconotide. ${ }^{46-49}$ Although the initial costs of IT drug therapy may be higher, these costs may be offset by maintenance costs that are subsequently lower than those associated with conventional therapy. ${ }^{48}$ Reimbursement and access programs, such as NAVIGATOR ${ }^{\circledR}$ (sponsored by the manufacturer of ziconotide), may be useful for further reducing patients' financial burdens and improving their ability to receive treatment.

\section{Appropriate use of IT drug delivery}

Given the complexity of IT drug delivery, a multidisciplinary group of skilled clinicians convenes every few years to offer guidelines on the use of this modality. The Polyanalgesic Consensus Conference (PACC) and others have recommended that IT drug delivery be considered an option for select patients requiring long-term management of refractory chronic pain states (Table 3). ${ }^{28,31,36,50,51}$ Substantial clinical evidence supports the efficacy and safety profiles of IT therapies in various pain states. ${ }^{28}$ Notably, reduction in pain, the use of systemic opioids, and drug-related toxicities have been reported from several trials of IT drug delivery. ${ }^{28,52}$ Additionally, a 3-year, controlled, prospective trial documented notable improvements in pain, mood, and function with IT opioid therapy, although less robust improvements in physical and mental functioning have been reported in other clinical experiences. ${ }^{28,33,53,54}$

The treating physician needs to consider the suspected site of pain origin and the feasibility of placing an IT catheter tip within sufficiently close proximity to ensure local drug concentrations in the cerebrospinal fluid are adequate to achieve

Table 3 Polyanalgesic Consensus Conference recommendations for the consideration of intrathecal drug delivery

- Axial low back pain

- Neuropathic pain, including diabetic neuropathy, postherpetic neuralgia, spinal cord injury, thalamic syndrome, cancer-related pain

- Radicular pain from failed back surgery syndrome

- Complex regional pain syndrome

- Spinal stenosis

- Osteoporosis

- Pancreatitis

- Phantom limb pain

- Compression fractures

- Other disorders associated with injury or irritation to the nervous system

Notes: Data from Deer et al, ${ }^{28}$ Deer et al, ${ }^{36}$ Deer $^{50}$, and Patel et al. ${ }^{51}$ effective pain relief. Available evidence supports the concept that the catheter tip must be placed within a few centimeters of the nerves associated with the pain source. ${ }^{31}$ In contrast, the prescribing information for IT morphine recommends administration in the lumbar region to reduce concerns about adverse effects. ${ }^{55}$ However, the authors' experience suggests that sites as high as $\mathrm{T} 1$ or $\mathrm{T} 2$, or even $\mathrm{C} 1$ or $\mathrm{C} 2$, may be used successfully with recognition of the potential adverse effects of catheter placement in these regions.

\section{Patient selection criteria for IT analgesia}

IT drug delivery provides the pain specialist with an important treatment option for patients with chronic, severe pain. To increase the opportunity for optimal outcomes, the pain specialist can take specific steps to identify those patients for whom IT therapy may be an appropriate choice and, secondarily, to consider patient characteristics that may help guide the choice of medication for IT delivery (Figure 1). ${ }^{28,31,36,38,50,56,57}$

The patient selection process begins with confirmation of the patient's diagnosis of chronic moderate to severe pain..$^{28}$ The presence of nociceptive, neuropathic, or mixed nociceptive-neuropathic pain states should be established, ${ }^{28,31}$ and the possibility of any correctable pathology should be evaluated and ruled out. The refractory nature of the patient's pain can be documented through a reasonable trial of conservative therapies before considering IT drug delivery. ${ }^{28}$ The patient should be asked about a history of failure on prior trials of systemic opioids to probe for the possibility of "opioid resistance". Medical professionals should note whether patients have ever needed high-dose opioids or rapid escalation of opioid dosages, because either type of event would be consistent with opioid resistance.

The possibility of opioid-induced hyperalgesia should also be explored in these patients. ${ }^{58}$ The pain specialist should learn how the patient defines "failure" (for example, a lack of efficacy despite increasing medication doses or poor tolerability) and probe for the possibility of a history of improper handling of opioids that could include abuse or diversion. The patient and caregiver must understand that any intervention, including IT drug delivery, may help to reduce pain and improve quality of life but will not "cure" the pain problem. The pain specialist can strengthen the working relationship with the patient by ensuring that the patient and caregiver understand this fact and agree on specific criteria for defining "treatment success" based on the patient's priority (for example, a change in pain intensity 


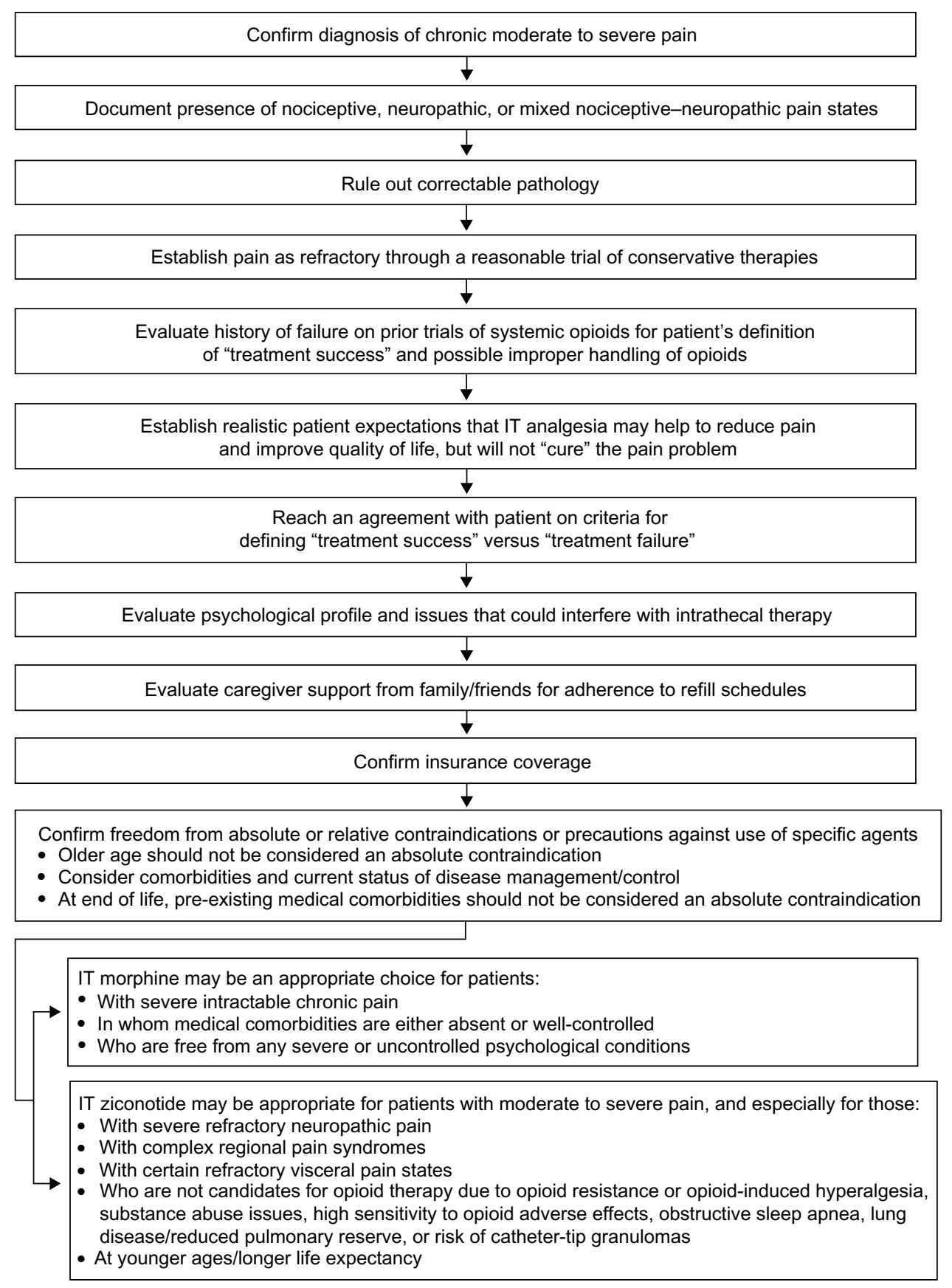

Figure I Considerations in selection of patients for IT drug delivery.

Note: Data from Deer et al; ${ }^{28}$ Deer et al; $;{ }^{31}$ Deer et al; ${ }^{36}$ Deer; ${ }^{50}$ Smith and Deer; ${ }^{56}$ and Schmidtko et al. ${ }^{57}$

Abbreviation: IT, intrathecal.

rating or an improvement in specific functionality). Patients can be informed that successful IT therapy may help to reduce their consumption of oral opioids and may help to reduce opioid-related adverse effects of constipation and hypogonadism.

In addition to other medical considerations, the pain specialist will need to evaluate psychological issues and other potential barriers to effective pain management in individual patients. The PACC recommends that, in addition to the workup recommended for all patients with refractory chronic pain, candidates for IT therapy should undergo a careful psychological evaluation that includes an assessment of the patient's stress management and coping skills before starting therapy, after trialing, and periodically during therapy. ${ }^{31}$ Each patient's psychological profile needs to be evaluated to confirm that he or she is ready to be an active participant in working toward an optimal clinical outcome and is free from psychological or cognitive issues that might interfere 
with IT therapy. Patients with refractory cancer pain who have failed more conservative approaches, and for whom quality of life may be substantially improved with effective pain management, may not need to undergo psychological evaluation. $^{31}$

Logistical issues, including caregiver support and insurance coverage, also need to be addressed at this time. Caregiving is important for the adequate monitoring of patients on IT therapy, especially among patients with risk factors such as psychiatric conditions or obstructive sleep apnea. ${ }^{31}$ In short, patients who are ideally suited for IT therapy include those who have caregiver support from family/friends and who do not have cognitive, psychological, or socioeconomic impediments to maintaining their refill schedules. $^{28}$

Although older age should not be considered an absolute contraindication to the use of IT therapy, younger versus older age may be a consideration in the choice of an IT agent. ${ }^{28}$ Limited evidence may suggest a greater responsiveness to opioids and reduced development of opioid tolerance among older versus younger patients, perhaps explained by a greater degree of neuroplasticity with youth. ${ }^{28,59}$ The authors of one retrospective analysis ${ }^{60}$ of patients with chronic noncancer pain urged greater caution in selecting younger patients (18-50 years of age) for IT opioid therapy due to findings suggestive of age-related differences in opioid tolerance of patients with chronic noncancer pain. Their analysis showed increased requirements for both IT and oral opioids among younger versus older patients ( $>50$ years of age) through 12 months postimplant.

In the absence of definitive clinical evidence, the relevance of age as a potential patient selection factor continues to be a subject of discussion and controversy. ${ }^{28,36,60}$ The authors of this paper perceive age as a potentially relevant patient selection factor based on currently available evidence, whereas others do not find this evidence sufficiently compelling to change clinical practice. Clearly, the appropriate role of age as a factor in the patient selection process, and its influence on the selection of a specific IT agent, can only be resolved through additional preclinical and clinical investigation.

\section{Nonpharmacologic risks of IT therapy}

In addition to the adverse effects related to the pharmacologic activities of IT morphine and ziconotide, patients also have a relatively low risk of experiencing certain procedural-, catheter-, and device-related safety issues. ${ }^{41,61}$ For example, obstructions or kinks in the catheter, or device malfunctions, can result in underdosing and cause a loss of analgesia or, in the case of IT morphine, symptoms of withdrawal. ${ }^{41}$ Additionally, when refilling the pump, the clinician may inadvertently inject the drug into the subcutaneous pocket, causing a "pocket fill", which increases exposure and can exacerbate concentrationdependent adverse effects or cause an overdose. ${ }^{41}$ Other device-related errors that can result in over- or underdosing include programming errors, miscalculating the quantity of drug needed to refill the pump, or utilizing an inappropriate dose when reinitiating therapy after a temporary cessation in treatment or when changing pumps. ${ }^{41}$ Following pump and catheter implantation, some patients may also experience transient spinal headache $(<2 \%)$, meningitis $(<3 \%)$, or other bacterial infections $(<10 \%){ }^{41,61}$ A prospective analysis of more than 200 patients receiving IT treatment during a mean of 8 months of follow-up demonstrated that the incidence of catheter-related complications was 0.05 events/patient-year (3.3\%), whereas the incidence of implantation procedurerelated complications was 0.29 events/patient-year (15.3\%). ${ }^{61}$ The most common events were infections, leaks, cuts, kinks, breaks, dislodgement, and migration of the catheter. The authors suggest that the risk of these events can be mitigated by using proper implantation techniques. ${ }^{61}$ To reduce the risk for morbidity and mortality associated with using IT therapy, the PACC recommends that physicians and other health care professionals receive adequate training in the proper implantation, refill, and management techniques that are associated with IT therapy, including didactic and hands-on training (for example, proctored implantations). ${ }^{41}$ To help reduce the risk for developing infections, the PACC recommends monitoring for factors that can increase the risk for infection, including poorly controlled blood sugar and a history of MRSA. ${ }^{41}$

\section{Selecting agents for IT therapy}

Patients who meet the general criteria for the appropriate IT drug delivery candidates can then be considered for treatment with a specific agent. With respect to specific medications, the PACC notes that only two agents - morphine (for example, INFUMORPH ${ }^{\circledR}$; West-Ward Pharmaceutical Corp., Eatontown, NJ, USA) and ziconotide (PRIALT ${ }^{\circledR}$; Jazz Pharmaceuticals Inc., Palo Alto, CA, USA) - are approved in the US for long-term IT infusion and are considered first-line agents for IT therapy. The PACC also considers the combination of morphine plus bupivacaine an option for first-line IT therapy in neuropathic pain, as well as hydromorphone and fentanyl as first-line agents for nociceptive pain, although these therapies are not approved by the US Food and Drug Administration. ${ }^{14,31,36,62}$ 
The pain specialist should evaluate the patient's status with regard to absolute or relative contraindications for or precautions against the use of specific agents delivered by the IT route. ${ }^{28}$ Additional factors, such as life expectancy and those involving the presence and management of comorbidities such as diabetes, cardiovascular disease, respiratory disease, depression, systemic infection, hypogonadism, and coagulopathy, may also need to be considered.

IT morphine may be an appropriate choice for patients with severe refractory chronic pain in whom preexisting medical comorbidities are either absent or well controlled, and who are free from any severe or uncontrolled psychological conditions. ${ }^{36}$ IT ziconotide may be appropriate for patients with moderate to severe chronic pain who are candidates for IT therapy and intolerant of or refractory to other treatment modalities.

Patients who are already receiving long-term IT opioids, high-dose opioids, or opioids at rapidly escalating doses, or those who have evidence of opioid-related adverse effects or opioid-induced hyperalgesia, may be candidates for ziconotide as an alternative to IT opioid therapy, since a change in the route of delivery from systemic to IT may not alleviate these issues. ${ }^{58}$ Patients who are not candidates for opioid therapy due to substance abuse issues, obstructive sleep apnea, lung disease/reduced pulmonary reserve, or risk of catheter-tip granulomas may also be appropriate candidates for IT ziconotide..$^{28,56,57}$ If new research shows that younger patients are more likely than older patients to develop opioid resistance or opioid-induced hyperalgesia, ziconotide may be preferred in these patients.

The approved indication for IT morphine is for the treatment of intractable chronic pain. This particular agent was developed specifically for use in continuous microinfusion devices to control severe cancer pain. ${ }^{55}$ The efficacy of IT morphine monotherapy has been examined in retrospective and cohort studies (number $[\mathrm{n}]=335$ ), and the efficacy of IT morphine in combination with ziconotide, bupivacaine, baclofen, and other agents has been evaluated for treating cancer or noncancer pain ( $\mathrm{n}=80$; total: 415$){ }^{31}$ These trials demonstrated substantial reductions in pain, as well as improvements in quality of life scores and perceptions of health status, and reductions in systemic opioid doses. ${ }^{31}$

With respect to safety, IT morphine has been associated with several potentially serious safety concerns, including respiratory depression, hypogonadism, peripheral edema, IT granulomas (which may lead to serious neurologic impairment, including paralysis), and withdrawal symptoms, along with potentially severe life-threatening complications that may result from the abrupt cessation of high-dose IT delivery due to catheter disruption, battery failure, or human error. ${ }^{8,28,31,55,63,64}$ Opioid analgesics may cause severe hypotension in certain patients, and the administration of IT morphine poses a risk of severe, potentially life-threatening respiratory depression; observation in a fully equipped and staffed environment is required for at least 24 hours after administration of the initial test dose and, as appropriate, for the first several days after the initiation of IT therapy. ${ }^{55}$ Accordingly, IT morphine should not be given to patients with chronic pulmonary disease, such as chronic asthma or upper airway obstruction, without full consideration of the known risks of respiratory depression and acute respiratory failure after the administration of morphine in these patients. ${ }^{55}$ IT morphine should be used with care in patients with decreased respiratory reserve due to emphysema, severe obesity, kyphoscoliosis, or paralysis of the phrenic nerve. ${ }^{55}$ IT morphine should also be used with care in patients who are immunosuppressed. ${ }^{28,31}$ Peripheral edema can develop in otherwise healthy patients receiving morphine (intraspinally or systemically) and can lead to vascular compromise or cellulitis. $^{31}$

In addition to tolerance, which is a common safety issue with long-term morphine administration, ${ }^{31}$ opioid withdrawal symptoms can result from the unintentional disruption of therapy. ${ }^{28}$ Inflammatory mass/granuloma formation at the catheter tip can interfere with or block drug delivery and result in the loss of analgesic efficacy or neurologic changes, which may be severe and associated with permanent paralysis. ${ }^{28}$ Reports in the medical literature suggest that this challenge occurs only in patients who receive IT opioids (predominantly morphine or hydromorphone) as monotherapy or in combination, or with the long-term administration of agents that are not approved for long-term IT use. ${ }^{9,28,43}$ Inflammatory masses appear to form on catheter tips as a manifestation of local degranulation of arachnoid mast cells in response to high local opioid concentrations. These masses can block opioid drug delivery and precipitate unintentional withdrawal, which may be associated with severe, longterm neurologic damage and permanent paralysis. ${ }^{28,41,43}$ Catheter failure due to structural problems (for example, dislodgment/migration, obstruction, occlusion, kinking, or breakage), pump failure due to battery failure, and human error that leads to improper or inadequate refilling of the drug reservoir (for example, "pocket fills" of the subcutaneous space around the pump) can also interfere with or disrupt IT morphine delivery and precipitate unintentional 
withdrawal. ${ }^{31,41,55}$ Other adverse effects of IT morphine include fluid retention, urinary retention, myoclonic jerks, and nausea/vomiting. ${ }^{31}$

Although IT trialing with morphine is common, the process can be complicated by route-conversion issues and by the potential need for the weaning of systemic opioids before trialing. Wide variances in current route-conversion ratios and the lack of a conversion standard create uncertainty about delivering equianalgesic doses and may increase safety concerns during conversion from systemic to IT morphine. ${ }^{31,65-67}$ For patients in whom these cautions raise important safety issues, nonopioid IT therapy, such as ziconotide, should be considered. ${ }^{28,31}$

Ziconotide is indicated for the management of severe chronic pain in adult patients for whom IT therapy is warranted, and who are intolerant of or refractory to other treatment, such as systemic analgesics, adjunctive therapies, or IT morphine. ${ }^{68}$ Ziconotide has shown efficacy across multiple types of pain etiologies. ${ }^{69,70}$ The efficacy and safety profiles of ziconotide monotherapy have been assessed in three double-blind, placebo-controlled trials of 457 patients with severe chronic pain, and safety has been assessed in 1,254 patients overall, and the findings have been supported by published case series in which ziconotide was administered as a monotherapy or in combination with other agents, including opioids. ${ }^{55,71-73}$ This experience documents clinically meaningful reductions in chronic pain, as well as improvements in functional capacity and reductions in systemic opioid usage in patients with refractory malignant or nonmalignant pain states. ${ }^{31,68}$ With respect to its safety profile, ziconotide has a narrow therapeutic window, which requires careful titration to determine the lowest possible dose for each patient that is therapeutic and sufficiently well tolerated. A high starting dose and/or rapid dose titration can result in adverse effects, including psychological/psychiatric abnormalities. ${ }^{31,74}$ Cognitive impairment involving mental slowing, confusion, difficulty concentrating, memory impairment, and impaired verbal expression, as well as new-onset psychosis and changes in consciousness are also possible. ${ }^{31}$ However, these adverse effects were most pronounced with the use of excessively high starting doses and aggressive titration schedules in early clinical trials of ziconotide in the $1990 \mathrm{~s} .{ }^{56,75}$ New slow titration protocols have reduced the risk of these adverse effects. ${ }^{31,56}$

Ziconotide is contraindicated in patients with a history of psychosis, hypersensitivity, or those with general contraindications to IT therapy, and the combination of IT ziconotide with IT opiates has not been extensively studied. ${ }^{31,68}$ However, across 15 clinical trials of 1,351 patients, only $22(1.6 \%)$ patients experienced psychosis events, and in only ten patients were these events considered related to ziconotide. ${ }^{76}$ Current recommendations for IT ziconotide treatment highlight the benefits of a slow titration plan to minimize the risk of psychiatric complications. ${ }^{31}$

Adverse effects reported with ziconotide include dizziness, gait abnormalities, headache, diplopia, urinary retention, nystagmus, speech disorder, nausea, nervousness, and somnolence. ${ }^{31}$ The concomitant use of ziconotide in patients taking antiepileptics, neuroleptics, sedatives, or diuretics may increase the risk of depressed levels of consciousness, and concomitant use with drugs that depress central nervous system activity may increase the risk of adverse effects, such as dizziness and confusion. ${ }^{68}$

Currently, pain specialists use several trialing methods for ziconotide. ${ }^{77}$ Since methods involving continuous infusion over multiple weeks, limited duration (1-hour) infusion, or bolus injection have not been directly compared against each other, pain specialists do not have a basis for deciding on the superiority of any one trialing approach. ${ }^{77}$ Nonetheless, the PACC recommends that, although trialing with bolus dosing may be productive in identifying some candidates for ziconotide, many other potential candidates who could also benefit from IT ziconotide may fail bolus trialing due to intolerable adverse effects. Proper hydration by means of intravenous infusion before the start of a trial may help limit the incidence of hypotension. ${ }^{31}$ Available data support slow titration trialing with ziconotide, because the incidence of adverse effects appears to correlate more closely with the rate of dosage change rather than the absolute dosage. ${ }^{31}$ In the absence of definitive clinical evidence, expert opinion supports continuous IT infusion for ziconotide trialing whenever feasible. ${ }^{77}$

\section{Conclusion}

Clinical evidence supports the view that IT drug delivery has a defined role as an option for appropriate patients with refractory chronic pain. Health care providers considering IT drug delivery as a treatment for their patients should ensure that their practices are positioned to meet the challenges of IT drug delivery and can fully accommodate all aspects of IT drug delivery. Recognition and use of important patient selection criteria, including treatment history, diagnosis, pathology, and age, along with cognitive, psychological, or socioeconomic status, can help guide and improve the successful management of chronic pain with IT therapy. 
IT morphine can be an appropriate choice for a patient whose pain is not responsive to non-narcotic analgesics. It provides documented efficacy, as a monotherapy or in combination, for improved functionality and the reduction of pain intensity, as well as for the need for systemic opioids. ${ }^{31}$ A patient's risk of potentially serious complications with IT morphine, such as respiratory depression, peripheral edema, granulomas, tolerance, and withdrawal, needs to be considered carefully. Notably, IT morphine should not be used in patients with chronic pulmonary disease, such as chronic asthma or upper airway obstruction, or any other chronic pulmonary disorder, without full consideration of the known risk of acute respiratory failure in these patients. Care should be used in patients with decreased respiratory reserve or those who are immunosuppressed. . $^{28,31,55}$

IT ziconotide can be an appropriate choice for patients with severe chronic, refractory nociceptive, neuropathic, or mixed neuropathic/nociceptive pain. It provides documented efficacy as a monotherapy, it may be effective in combination with other medications to reduce pain intensity and improve functionality, and it may reduce the need for systemic opioids. ${ }^{31}$ Ziconotide also provides the pain specialist with an important alternative to morphine, to avoid opioidrelated respiratory depression in patients with lung disease/ compromised respiratory reserve or peripheral edema, and in patients with opioid resistance who require high doses or rapidly escalating doses, or who develop opioid-induced hyperalgesia. Unlike morphine and other opioids, ziconotide is not associated with issues of tolerance, withdrawal, or granulomas, which can have major deleterious effects. ${ }^{31}$

\section{Acknowledgments}

Financial support for medical editorial assistance was provided by Jazz Pharmaceuticals. We thank David K Schroeder, Synchrony Medical Communications, LLC, West Chester, PA, USA for his medical editorial assistance with this manuscript.

\section{Author contributions}

All authors participated equally and fully in the conception of the ideas and the selection of the material presented in this manuscript, contributed to all drafts, and approved the final manuscript for submission.

\section{Disclosure}

Michael Saulino, $\mathrm{MD}, \mathrm{PhD}$, reports receiving research grants from CNS Therapeutics and Medtronic, Inc.; serving on the speakers' bureau for Medtronic, Inc.; and receiving a consultancy fee or honorarium from Jazz Pharmaceuticals, Medtronic, Inc., and SPR Therapeutics. Philip S Kim, MD, serves on the speakers' bureau and as a consultant for Medtronic and Jazz Pharmaceuticals. Erik Shaw, DO, serves on the advisory board and speakers' bureau for Jazz Pharmaceuticals. The authors report no other conflicts of interest in this work.

\section{References}

1. Institute of Medicine of the National Academies. Relieving Pain in America: A Blueprint for Transforming Prevention, Care, Education, and Research. Washington, DC: National Academies Press; 2011.

2. Breivik H, Collett B, Ventafridda V, Cohen R, Gallacher D. Survey of chronic pain in Europe: prevalence, impact on daily life, and treatment. Eur J Pain. 2006;10(4):287-333.

3. Practice guidelines for chronic pain management. A report by the American Society of Anesthesiologists Task Force on Pain Management, Chronic Pain Section. Anesthesiology. 1997;86(4): 995-1004.

4. Bair MJ, Wu J, Damush TM, Sutherland JM, Kroenke K. Association of depression and anxiety alone and in combination with chronic musculoskeletal pain in primary care patients. Psychosom Med. 2008;70(8): 890-897.

5. Gureje O. Comorbidity of pain and anxiety disorders. Curr Psychiatry Rep. 2008;10(4):318-322.

6. Boersma K, Linton SJ. Psychological processes underlying the development of a chronic pain problem: a prospective study of the relationship between profiles of psychological variables in the fearavoidance model and disability. Clin J Pain. 2006;22(2):160-166.

7. Okifuji A, Turk DC, Curran SL. Anger in chronic pain: investigations of anger targets and intensity. J Psychosom Res. 1999;47(1):1-12.

8. Stein C, Kopf A. Anesthesia and treatment of chronic pain. In: Miller RD, Eriksson LI, Fleisher LA, Wiener-Kronish JP, Young WL, editors. Miller's Anesthesia. 7th ed. London, UK: Churchill Livingstone, Elsevier; 2009:1797-1818.

9. Manchikanti L, Abdi S, Atluri S, et al. An update of comprehensive evidence-based guidelines for interventional techniques in chronic spinal pain. Part II: guidance and recommendations. Pain Physician. 2013;16(Suppl 2):S49-S283.

10. American Society of Anesthesiologists Task Force on Chronic Pain Management; American Society of Regional Anesthesia and Pain Medicine. Practice guidelines for chronic pain management: an updated report by the American Society of Anesthesiologists Task Force on Chronic Pain Management and the American Society of Regional Anesthesia and Pain Medicine. Anesthesiology. 2010;112(4):810-833.

11. Chou R, Atlas SJ, Stanos SP, Rosenquist RW. Nonsurgical interventional therapies for low back pain: a review of the evidence for an American Pain Society clinical practice guideline. Spine (Phila Pa 1976). 2009;34(10):1078-1093.

12. Chou R, Baisden J, Carragee EJ, Resnick DK, Shaffer WO, Loeser JD. Surgery for low back pain: a review of the evidence for an American Pain Society Clinical Practice Guideline. Spine (Phila Pa 1976). 2009;34(10):1094-1109.

13. Luijsterburg PA, Verhagen AP, Ostelo RW, van Os TA, Peul WC, Koes BW. Effectiveness of conservative treatments for the lumbosacral radicular syndrome: a systematic review. Eur Spine J. 2007;16(7): 881-899.

14. Turk DC, Wilson HD, Cahana A. Treatment of chronic non-cancer pain. Lancet. 2011;377(9784):2226-2235.

15. Rauck R, Coffey RJ, Schultz DM, et al. Intrathecal gabapentin to treat chronic intractable noncancer pain. Anesthesiology. 2013;119(3): 675-686.

16. Gatchel RJ, Okifuji A. Evidence-based scientific data documenting the treatment and cost-effectiveness of comprehensive pain programs for chronic nonmalignant pain. J Pain. 2006;7(11):779-793. 
17. Guzmán J, Esmail R, Karjalainen K, MalmivaaraA, Irvin E, Bombardier C. Multidisciplinary bio-psycho-social rehabilitation for chronic low back pain. Cochrane Database Syst Rev. 2002;(1):CD000963.

18. Stanos SP, McLean J, Rader L. Physical medicine rehabilitation approach to pain. Anesthesiol Clin. 2007;25(4):721-759, vi.

19. van Tulder M, Malmivaara A, Esmail R, Koes B. Exercise therapy for low back pain: a systematic review within the framework of the Cochrane Collaboration Back Review Group. Spine (Phila Pa 1976). 2000;25(21): 2784-2796.

20. Hoffman MD, Hoffman DR. Does aerobic exercise improve pain perception and mood? A review of the evidence related to healthy and chronic pain subjects. Curr Pain Headache Rep. 2007;11(2):93-97.

21. Kerns RD, Sellinger J, Goodin BR. Psychological treatment of chronic pain. Annu Rev Clin Psychol. 2011;7:411-434.

22. Hoffman BM, Papas RK, Chatkoff DK, Kerns RD. Meta-analysis of psychological interventions for chronic low back pain. Health Psychol. 2007;26(1):1-9.

23. Bercovitz A, Sengupta M, Jones A, Harris-Kojetin LD. Complementary and alternative therapies in hospice: the National Home and Hospice Care Survey: United States, 2007. National Health Statistics Reports; no 33. Hyattsville, MD: National Center for Health Statistics; 2010.

24. National Institutes of Health National Center for Complementary and Alternative Medicine. Chronic Pain and CAM: At a Glance. Bethesda, MD: National Center for Complementary and Alternative Medicine; 2011.

25. Dworkin RH, O'Connor AB, Audette J, et al. Recommendations for the pharmacological management of neuropathic pain: an overview and literature update. Mayo Clin Proc. 2010;85(Suppl 3):S3-S14

26. Kroenke K, Krebs EE, Bair MJ. Pharmacotherapy of chronic pain: a synthesis of recommendations from systematic reviews. Gen Hosp Psychiatry. 2009;31(3):206-219.

27. Staal JB, de Bie RA, de Vet HC, Hildebrandt J, Nelemans P. Injection therapy for subacute and chronic low back pain: an updated Cochrane review. Spine (Phila Pa 1976). 2009;34(1):49-59.

28. Deer TR, Smith HS, Burton AW, et al; Center For Pain Relief, Inc. Comprehensive consensus based guidelines on intrathecal drug delivery systems in the treatment of pain caused by cancer pain. Pain Physician 2011;14(3):E283-E312.

29. Ballantyne JC, Shin NS. Efficacy of opioids for chronic pain: a review of the evidence. Clin J Pain. 2008;24(6):469-478.

30. Dillie KS, Fleming MF, Mundt MP, French MT. Quality of life associated with daily opioid therapy in a primary care chronic pain sample. J Am Board Fam Med. 2008;21(2):108-117.

31. Deer TR, Prager J, Levy R, et al. Polyanalgesic Consensus Conference 2012: recommendations for the management of pain by intrathecal (intraspinal) drug delivery: report of an interdisciplinary expert panel. Neuromodulation. 2012;15(5):436-464; discussion 464-466.

32. Gerber HR. Intrathecal morphine for chronic benign pain. Best Pract Res Clin Anaesthesiol. 2003;17(3):429-442.

33. Thimineur MA, Kravitz E, Vodapally MS. Intrathecal opioid treatment for chronic non-malignant pain: a 3-year prospective study. Pain. 2004;109(3):242-249.

34. Bennett G, Burchiel K, Buchser E, et al. Clinical guidelines for intraspinal infusion: report of an expert panel. PolyAnalgesic Consensus Conference 2000. J Pain Symptom Manage. 2000;20(2):S37-S43.

35. Deer TR, Krames E, Levy RM, Hassenbusch SJ 3rd, Prager JP. Practice choices and challenges in the current intrathecal therapy environment: an online survey. Pain Med. 2009;10(2):304-309.

36. Deer TR, Smith HS, Cousins M, et al. Consensus guidelines for the selection and implantation of patients with noncancer pain for intrathecal drug delivery. Pain Physician. 2010;13(3):E175-E213.

37. Sullivan MJ, Thorn B, Haythornthwaite JA, et al. Theoretical perspectives on the relation between catastrophizing and pain. Clin J Pain. 2001;17(1):52-64.
38. Deer TR, Prager J, Levy R, et al. Polyanalgesic Consensus Conference - 2012: recommendations on trialing for intrathecal (intraspinal) drug delivery: report of an interdisciplinary expert panel. Neuromodulation. 2012;15(5):420-435; discussion 435.

39. Centers for Disease Control and Prevention. Antibiotic Resistance Threats in the United States, 2013. Atlanta, GA: US Department of Health and Human Services, Centers for Disease Control and Prevention; 2013.

40. Centers for Disease Control and Prevention. Active Bacterial Core Surveillance (ABCs) Report Emerging Infections Program Network: Methicillin-Resistant Staphylococcus Aureus. Atlanta, GA: Centers for Disease Control and Prevention; 2011. Available from: http:// www.cdc.gov/abcs/reports-findings/survreports/mrsa11.pdf. Accessed September 17, 2013

41. Deer TR, Levy R, Prager J, et al. Polyanalgesic Consensus Conference - 2012: recommendations to reduce morbidity and mortality in intrathecal drug delivery in the treatment of chronic pain. Neuromodulation. 2012;15(5):467-482; discussion 482

42. Deer TR. Polyanalgesic Consensus Conference 2012. Neuromodulation. 2012;15(5):418-419.

43. Deer T, Krames ES, Hassenbusch SJ, et al. Polyanalgesic consensus conference 2007: recommendations for the management of pain by intrathecal (intraspinal) drug delivery: report of an interdisciplinary expert panel. Neuromodulation. 2007;10(4):300-328.

44. de Lissovoy G, Brown RE, Halpern M, Hassenbusch SJ, Ross E. Cost-effectiveness of long-term intrathecal morphine therapy for pain associated with failed back surgery syndrome. Clin Ther. 1997;19(1):96-112; discussion 84-85.

45. Kumar K, Hunter G, Demeria DD. Treatment of chronic pain by using intrathecal drug therapy compared with conventional pain therapies: a cost-effectiveness analysis. J Neurosurg. 2002;97(4):803-810.

46. Kumar K, Rizvi S, Bishop S. Cost effectiveness of intrathecal drug therapy in management of chronic nonmalignant pain. Clin J Pain. 2013;29(2):138-145.

47. Kumar K, Rizvi S, Bishop S, Tang W. Cost impact of intrathecal polyanalgesia. Pain Med. 2013;14(10):1569-1584.

48. Brogan SE, Winter NB, Abiodun A, Safarpour R. A cost utilization analysis of intrathecal therapy for refractory cancer pain: identifying factors associated with cost benefit. Pain Med. 2013;14(4): 478-486.

49. Dewilde S, Verdian L, Maclaine GD. Cost-effectiveness of ziconotide in intrathecal pain management for severe chronic pain patients in the UK. Curr Med Res Opin. 2009;25(8):2007-2019.

50. Deer TR. An overview of interventional spinal techniques. Seminars in Pain Medicine. 2004;2(3):154-166.

51. Patel VB, Manchikanti L, Singh V, Schultz DM, Hayek SM, Smith HS. Systematic review of intrathecal infusion systems for longterm management of chronic non-cancer pain. Pain Physician. 2009;12(2):345-360.

52. Staats PS, Yearwood T, Charapata SG, et al. Intrathecal ziconotide in the treatment of refractory pain in patients with cancer or AIDS: a randomized controlled trial. JAMA. 2004;291(1):63-70.

53. Molloy AR, Nicholas MK, Asghari A, et al. Does a combination of intensive cognitive-behavioral pain management and a spinal implantable device confer any advantage? A preliminary examination. Pain Pract. 2006;6(2):96-103.

54. Cohen SP, Dragovich A. Intrathecal analgesia. Anesthesiol Clin. 2007;25(4):863-882, viii.

55. INFUMORPH 200, INFUMORPH 500 (preservative-free morphine sulfate sterile solution) [package insert]. Deerfield, IL: Baxter Healthcare Corporation; 2004.

56. Smith HS, Deer TR. Safety and efficacy of intrathecal ziconotide in the management of severe chronic pain. Ther Clin Risk Manag. 2009;5(3):521-534.

57. Schmidtko A, Lötsch J, Freynhagen R, Geisslinger G. Ziconotide for treatment of severe chronic pain. Lancet. 2010;375(9725): $1569-1577$. 
58. Walker MJ, Webster LR. Opioid-induced hyperalgesia and monotherapy intrathecal ziconotide: experience with four cases. J Pain Manag. 2013;6(3):257-264.

59. Buntin-Mushock C, Phillip L, Moriyama K, Palmer PP. Age-dependent opioid escalation in chronic pain patients. Anesth Analg. 2005;100(6): $1740-1745$

60. Hayek SM, Veizi IE, Narouze SN, Mekhail N. Age-dependent intrathecal opioid escalation in chronic noncancer pain patients. Pain Med. 2011;12(8):1179-1189.

61. Follett KA, Naumann CP. A prospective study of catheter-related complications of intrathecal drug delivery systems. J Pain Symptom Manage. 2000;19(3):209-215.

62. Manchikanti L, Boswell MV, Datta S, et al; ASIPP. Comprehensive review of therapeutic interventions in managing chronic spinal pain. Pain Physician. 2009;12(4):E123-E198.

63. Colameco S, Coren JS. Opioid-induced endocrinopathy. J Am Osteopath Assoc. 2009;109(1):20-25.

64. De Maddalena C, Bellini M, Berra M, Meriggiola MC, Aloisi AM. Opioid-induced hypogonadism: why and how to treat it. Pain Physician. 2012;15(Suppl 3):ES111-ES118.

65. Duramorph ${ }^{\circledR}$ (morphine sulfate injection, USP) [package insert]. Eatontown, NJ: West-Ward Pharmaceutical Corp; 2011.

66. Sylvester RK, Lindsay SM, Schauer C. The conversion challenge: from intrathecal to oral morphine. Am J Hosp Palliat Care. 2004;21(2):143-147.

67. Shaheen PE, Walsh D, Lasheen W, Davis MP, Lagman RL. Opioid equianalgesic tables: are they all equally dangerous? J Pain Symptom Manage. 2009;38(3):409-417.

68. PRIALT ${ }^{\circledR}$ (ziconotide) solution, intrathecal infusion [package insert]. Palo Alto, CA: Jazz Pharmaceuticals, Inc.; 2013.

69. Wallace MS, Charapata SG, Fisher R, et al; Ziconotide Nonmalignant Pain Study 96-002 Group. Intrathecal ziconotide in the treatment of chronic nonmalignant pain: a randomized, double-blind, placebo-controlled clinical trial. Neuromodulation. 2006;9(2):75-86.
70. Rauck RL, Wallace MS, Leong MS, et al; Ziconotide 301 Study Group. A randomized, double-blind, placebo-controlled study of intrathecal ziconotide in adults with severe chronic pain. J Pain Symptom Manage. 2006;31(5):393-406.

71. Wermeling DP, Berger JR. Ziconotide infusion for severe chronic pain: case series of patients with neuropathic pain. Pharmacotherapy. 2006;26(3):395-402.

72. Saulino M, Burton AW, Danyo DA, Frost S, Glanzer J, Solanki DR. Intrathecal ziconotide and baclofen provide pain relief in seven patients with neuropathic pain and spasticity: case reports. Eur J Phys Rehabil Med. 2009;45(1):61-67.

73. Kapural L, Lokey K, Leong MS, et al. Intrathecal ziconotide for complex regional pain syndrome: seven case reports. Pain Pract. 2009;9(4):296-303.

74. Maier C, Gockel HH, Gruhn K, Krumova EK, Edel MA. Increased risk of suicide under intrathecal ziconotide treatment? - a warning. Pain. 2011;152(1):235-237.

75. Fisher R, Hassenbusch S, Krames E, et al. A consensus statement regarding the present suggested titration for Prialt (ziconotide). Neuromodulation. 2005;8(3):153-154.

76. Caraway D, Saulino MF, Kim P, Hockett S, Alvarez-Horine S. Characterization of psychotic events in patients on intrathecal ziconotide for severe chronic pain. Poster presented at: North American Neuromodulation Society; December 5-8, 2013; Las Vegas, NV.

77. Burton AW, Deer TR, Wallace MS, Rauck RL, Grigsby E. Considerations and methodology for trialing ziconotide. Pain Physician. 2010;13(1):23-33.
Journal of Pain Research

\section{Publish your work in this journal}

The Journal of Pain Research is an international, peer-reviewed, open access, online journal that welcomes laboratory and clinical findings in the fields of pain research and the prevention and management of pain. Original research, reviews, symposium reports, hypothesis formation and commentaries are all considered for publication.

\section{Dovepress}

The manuscript management system is completely online and includes a very quick and fair peer-review system, which is all easy to use. Visit http://www.dovepress.com/testimonials.php to read real quotes from published authors. 